\title{
STYLISTIC FEATURES OF BRITISH NEWSPAPER HEADLINES IN THE DIACHRONIC ASPECT
}

\begin{abstract}
Alesia Shevtsova ${ }^{2}$
Abstract: The paper focuses on the tendencies in the linguistic evolution of newspaper headlines in the diachronic aspect - of two time periods: the beginning of the $20^{\text {th }}$ and the $21^{\text {st }}$ centuries. The article considers the structural types of newspaper headlines, their stylistic composition and predominant expressive means. On the basis of the obtained results an attempt to identify the main pragmatic function of the excerpted headlines has been made.
\end{abstract}

Key words: media discourse, newspaper headline, expressive means, pragmatic function, diachronic aspect.

\section{Introduction}

Media discourse represents current tendencies in the development of any national language. The proof of this idea is the suggestion to consider BBC English as the standard variant of the English language. At the same time, media discourse is not stable. It is in its constant development and evolution. The norms of the mass-media are changing so rapidly that scholars do not manage to present them in the dictionaries; moreover, they are often quite affected by individual styles in operating with the language.

Journalistic discourse makes a part in the paradigm of the media discourse. It is the oldest and most traditional among the other genres of the more general media discourse. Newspapers and magazines have been changing their "paper life-span" for digital one. This technical process is going hand in hand with the change of its pragmatic side and the roles they play of manipulation and commercialization as revealed by E. Herman and N. Chomsky (2002). Discourse

1. The research was carried out within the framework of the research and development program "Trends in the development and functioning of the Belarusian-language media discourse in the context of globalization and intercultural dialogue" (State registration No. 20161437) of the subprogram "Belarusian language and literature" of the state program of research "Economy and Humanitarian Development of the Belarusian Society" for 20162020 .

2. Associate professor, PhD at Mogilev State A. Kuleshov University, Belarus, e-mail: alice_shev@mail.ru 
analysts have been attracted by the linguistic realization of headlines as the main tools of the functions mentioned above.

Headlines are very specific structural units of texts. They are studied as independent and effective persuasive elements of articles [...] They are the first elements of articles the readers face and, to a great extent, they determine the interpretation of texts. It is essential for journalists to implement the most powerful persuasion strategies in the headlines of articles, as very often readers only look through the headlines and stop to read those articles with the most attractive headings (Marcoci, 2014).

\section{Previous research in the field}

In scientific literature newspaper headlines are analyzed from different perspectives. Teun A. van Dijk (1985, pp. 69-93) has studied the thematic and schematic structures of news from a discourse analytic point of view, drawing the conclusion that news should be studied only in the cognitive and sociocultural contexts embracing all their structural elements, including headlines. The scholar believes that headlines have a very specific thematic function: they usually express the most important topic of the news item (van Dijk, 1985, p. 69). Headlines and lead may therefore be used as expedient signals to make effective guesses about the most important information of the text. However, they express the macrostructure of the writer, rather than that of the reader: the reader may infer a different thematic structure, depending on his/ her own beliefs and attitudes. And when a headline or lead does not provide an adequate summary of the full overall meaning of a text, we may, either formally or subjectively, say that they are biased (van Dijk, 1985, p. 69). Radostina Iglikova calls headlines "labels" of the actual content of articles (Iglikova, 2017, p. 71), and she mentions the practical importance of studying the effectiveness of headlines - what features a headline should possess in order to achieve its main goal, i.e. to attract readers to the content of the article (Iglikova, 2018, p. 59). The researcher also studies the differences between the traditional headlines of the print press and those used in the web which belong to the representation of New Media.

Danuta Reah indicates the ephemeral nature of newspaper texts, that is, the fact that they are intended only for the day they are delivering the news (Reah, 2001, p.13).

The headlines have the capacity to encapsulate a story, and the headlines in a particular edition give the reader the overall picture of the current news, its relative importance, its classification (Reah, 2001, p.14). The researcher points out the main tendencies in the linguistic realization of headlines: headlines play on the potential for ambiguity that can exist in the relationship between words 
and meaning; frequent use of intertextuality; appeal to the reader's awareness of sound (phonological aspect); selection of words that carry particularly strong connotations - an emotional loading beyond their literal meaning (Reah, 2001, p. 17).

Shaeda Isani shares the idea of the unique reputation of the British press in the area of headline creativity. The researcher adopts two parallel terms - headlines as a sub-genre which is proposed to distinguish from the parent genre by the term "headlinese". The latter is viewed as the genre construct with regard to headlines focusing on their communicative functions (Isani, 2011). According to Daniel Dor (2003), headlines provide the readers with the optimal ratio between contextual effect and processing effort, and direct readers to construct the optimal context for interpretation. D. Dor explains that the construction of a successful headline requires the understanding of the readers - their state of knowledge, their beliefs and expectations and their cognitive styles (Dor, 2003, p. 696). As relevance-optimizers and relevance-based selection-devices, headlines function as negotiators between stories and readers. The researcher states that the headline is neither a semantic summary of the story nor a pragmatic attracting-device for the reader, but a communicative device whose function is to produce the optimal level of affinity between the content of the story and the reader's context of interpretation, in order to render the story optimally relevant for the reader (Dor, 2003, p. 720).

Akshay Gattani (2007) singles out three main types of headlines according to their functions: indicative headlines indicate what topics are covered by the news story; informative headlines convey what particular concept, theme or event is covered in the news story and eye-catchers do not inform about the content of the story but are designed to attract attention and entice people to read the story (Gattani, 2007, p. 13). The researcher studies the possible ways to generate natural language headlines automatically with the help of a computer program. In this respect it would be useful to consider the tendencies in the development of the linguistic realization of headlines.

The issue of different and common characteristics in the verbalization of headlines in different linguo-cultures has already been discussed from various perspectives and in combinations of different languages. For example, Kniffka (1980) identified regular structures of headlines across German and American English texts. But, as Christine Develotte and Elizabeth Rechnieweski state, the majority of studies analyze headlines from only one country (Develotte \& Rechnieweski, 2002, pp. 173-190): Allan Bell analyzes the "distinctive telegraphic syntax" of English newspaper headlines (Bell, 1989, p.185). Ingrid Mardh (1980) discusses a whole range of typical linguistic features of English newspapers: the omission of articles; the omission of verbs and of auxiliaries; nominalisations; the frequent use of complex noun phrases in subject position; 
adverbial headlines, with the omission of both verb and subject; the use of short words; the widespread use of puns, word play and alliteration; the importance of word order, with the most important items placed first, even, in some cases, a verb (Mardh, 1980). Morrow (2012) as quoted by Radostina Iglikova (Iglikova, 2018 , p. 60) proposes several patterns to organize headlines and gives his classification of headlines: threat headlines, zen headlines, piggyback headlines, mistake headlines, how to headlines, list headlines.

Christine Develotte and Elizabeth Rechnieweski (2001) operate with the term "national representations" when they affirm that headlines refer to the knowledge systems that encapsulate data about our own or any other nation. The researchers believe that the interrelation between these two categories of representation, the contrasts and binary oppositions that can be created, and the role played by representations of the other in defining one's own nationality and identity, these are issues which we have explored elsewhere (Develotte \& Rechnieweski, 2002). The scholars suggest three specific linguistic features relevant to the analysis of national representations: designation - the process of naming; appraisal the process of characterization and evaluation; presupposition - reference to the elements in discourse which are presupposed (Develotte \& Rechnieweski, 2001).

Tatiana Vorontsova (2017, p. 21) shares the idea that the main function of headlines is to form the initial image of the event described in the article. The researcher analyses the main causes of the deformation of the image of the event: a part of the event is presented as an independent event; a shift of semantic accents; incorrect or misleading choice of language means, intentional negative coloring of the image of the event (Vorontsova, 2017, pp. 21-25). The enumerated ways to distort the correct understanding of the presented event are used for the manipulation of the readers.

\section{Research Questions}

The present research aims at showing how the linguistic content and pragmatic functions of newspaper headlines are changing in time, what linguistic means and stylistic devices are involved to achieve the desired effect and impact on the targeted audience. A special attention is paid to the role of different structural types of newspaper headlines, the interconnection between the identified types and pragmatic functions of headlines. There is a hypothesis that the pragmatic role of the newspaper headline has been changing. Moreover, it has not been revealed yet what the balance between the two main functions of newspaper headlines is - informative and manipulative (eye-catching/ opinion-forming, and so on), and what linguistic means are used to realize these functions. 


\section{Methods}

The methods used for the analysis are the method of logical and comparative analysis, the elements of quantitative analysis, contextual analysis as well as the method of interpretation.

\section{Data Analysis}

The paper is a part of a bigger study embracing data from several typologically different languages: English, Russian and Belarusian, French. Within this paper we are focusing our attention on the dynamic character and evolution of stylistic features of the newspaper headlines in English. As the language of media discourse changes quite rapidly we consider that it is possible to reveal a number of new tendencies throughout a century. So the material for the analysis consists of excerpts of newspaper headlines from British (predominantly London) print press from the end of the nineteenth century and the beginning of the twentieth century (the Globe, the Times, Daily Mirror) - for the past period; and the headlines from the fresh print press of 2019 (the Times, the Guardian). A total of 400 English language headlines have been used to study the structural organization and stylistic content focusing on the domineering pragmatic functions.

The analysis of the stylistic peculiarities of the excerpted newspaper headlines of the two defined periods is based on the modern approach towards the understanding of stylistics in general and functional stylistics in particular. Margarita Kozhina (2011) defines stylistics as a linguistic science of the means of speech expressiveness and the laws governing the functioning of language, due to the appropriate use of language units depending on the content of the utterance, goals, situation, sphere of communication and other extra-linguistic factors. Within the frames of functional stylistics, the central purpose of the analysis is to identify which multi-level linguistic and speech means realize the basic functions of different types of speech works (functional styles, sub-styles, genres), how the extra-linguistic basis of styles influences the formation of speech organization, speech systematic styles. Margarita Kozhina also singles out diachronic and comparative stylistics as branches (varieties) of the stylistics of resources and functional stylistics (Kozhina, 2011). The methodology suggested by the researcher allowed to identify the procedure of the analysis presented in the paper.

The main task at the first stage of the analysis is to determine the main structures of the excerpted newspaper headlines of the two periods and their semantic load. This is followed by a careful study of all the details and features of the headlines. According to Margarita Kozhina, style is a phenomenon that can only 
be understood when considering goals, objectives, situations and the sphere of communication and the very content of the utterance (Kozhina, 2011).

\section{Key Findings}

The excerpted headlines of the past period can be classified into several structural groups: mononuclear nominative headlines (32\%); headlinessentences which include both a subject and a predicate (26\%); complex headlines with crossheadings (20\%); compound asyndetic headlines (8\%); interrogative headlines (7\%) and headlines-quotations (4\%). There are some other types $(3 \%)$ which are used sporadically (ex. mononuclear infinitive, etc.). We have not assigned them as separate classes for analysis as we focused our attention on the most frequently used types.

Mononuclear nominative headlines are predominant among the other types of the headlines selected from the newspapers of a century ago. The informative function of the headlines is realized through simple naming of events: Gloom in Buenos Aires; Chronicle of the conflict; Cheap return tickets to the East; Government's proposals; Statements in Commons; Arrests in Cairo; The true wireless by Nikola Tesla. However mononuclear nominative headlines also embrace exclamations which consist of a noun or nouns with some descriptive lexical elements: The great Boston Molasses flood!; Wall Street crash! Black Thursday in America. Although in general exclamative headlines are more or less stylistically neutral as they do not contain a great number of expressive means, in the examples presented herewith this type of headlines sound more emotional and realize the eye-catching function.

The second type - headlines-sentences which include both a subject and a predicate - is characterized by a greater potential capacity to effect readers' feeling and emotions. There have been identified different stylistic devices. On the phonetic level the most popular device is alliteration (The team led from tragedy to triumph). On the lexical and syntactic levels - epithets (Batchy dog shot after biting girl), metaphors (Firm US grip on Pacific Islands; Germans in a trap), metonymies (Belgium not satisfied; Washington welcomes end to the fighting; America expects actions). The concentration of expressive means and stylistic devices in the headlines of this type is not too high. They are registered in about $30 \%$ of the excerpted newspaper headlines. The majority of the material of this type is quite neutral and is aimed at information sharing, ex. Man of 80 charged with the murder of his wife; World tallest building opens.

Complex headlines with crossheadings were quite popular in newspapers a century ago. The lead was not so widely spread in the articles of that time, and journalists tried to specify the information in the main headline with the help of smaller in size subheadings, or crossheadings: Alcock and Brown fly across 
Atlantic. Make 1,980 miles in 16 hours, 12 minutes. Sometimes upside down in dense, icy fog; Titanic sinks. Great loss of life. World's greatest liner strikes iceberg. The complexes of two or more sentences facilitated the provision of information presented in the core of the articles, ex. Lord Hardinge for peace table. F.O. Head as British delegate. First meeting may sit twelve days hence. The headlines of the type are characterized by a number of stylistic devices alliterations (Premier's important announcement to conference of masters and men. Hours bill being drafted); epithets (Huns' last word. Hypocritical excuses of Wily Germans for atrocities. Pamphlet for prisoners); antithesis (Hours and wages decision. Minimum wages and maximum hours for all); metaphors (Petrograd may fall soon. Story of Bolshevik evacuation. Finns cut railway).

Compound asyndetic headlines consist of two or three interconnected parts but still they make one headline entity. These parts complement each other and give a more detailed picture of the event presented in the article. For example: Barbers' strike: latest siege of Posen: Paderewski as army leader or Italian Cabinet crisis over 1919: high hopes - and some fears. The elements of such compound asyndetic headlines can be of equal value - the presentation of several events, their enumeration. In some cases, still the parts can be semantically disparate. For example, a headline from a rather later newspaper of the World War II period: Churchill to Stalin: I had to speak my mind: Moscow talks cordial. Here the first two parts present main personages and the thoughts or words of one of them. And the third element is a sort of conclusion - the attitude of the journalist, his subjective interpretation of the described situation

Separate independent interrogative headlines and headlines-quotations are used quite rarely. More often they comprise a part of compound asyndetic headlines or complex headlines with crossheadings: Another axe attack? Wife found badly injured: husband missing; King Albert at council of ministers: "extremely strong measures"; "Strong measures". Won't-sign-treaty threat repeated;"How I flew the Atlantic" by Capt. Alcock. Britain's magnificent Atlantic air triumph.

As the conducted analysis has shown only about $35 \%$ of all types of the excerpted headlines of the past period contain stylistic devices and expressive means. The most popular among them is alliteration: Death and devastation in wake of North end disaster. Alliteration is a "very English" means that has been a principal ornamental tool to help indicate the underlying metrical structure as opposed to rhyme in alliterative verse in the oldest literature in English (Beowulf, Sir Gawain and the Green Knight, etc.). Since that time alliteration has been the preferred choice to create a musical effect in the text that enhances the pleasure of reading a whole article. It creates an attractive and appealing image of the text.

One more peculiar detail about the English headlines of the past period is that they occasionally contain non-assimilated French lexical items: Grand opening 
ceremony of the Eiffel Tower in Paris. Monsieur Eiffel has created the Wonder of the Age with the tallest tower in the World for the Exposition Universelle; Messageries maritimes de France (a company dispatches mail steamers to France). I can assume that some inclusions of French lexemes are intended to create the authentic atmosphere of the news covered in the articles, moreover this fact can point out close cultural and social links between France and Great Britain at that time.

As regards the excerpted headlines of the modern period (2019), we must admit that the trend observed is of a more limited range of frequently used types of headlines. We have singled out 4 main classes: simple headlines-sentences which include both a subject and a predicate (36\%); headlines-quotations (20\%); mononuclear nominative headlines (15\%) and compound headlines with semantically coordinated or subordinate elements (12\%). Complex headlines with crossheadings have become rare in use (3\%, ex. My nuclear button is bigger than yours. Trump taunts Kim as he steps up war of words with North Korea tyrant) against the increased amount of full extended headlines-sentences with subjects, predicates and other sentence parts. In the modern press there quite often occur imperative sentences with a single infinitive (4\%, ex. Beware the posh boy's hollow self-confidence) and independent questions (6\%) as headlines. These are rhetorical questions or questions addressed to the readers: When your local has praises like this to sing who needs a juke box?; Will history judge May to be our worst prime minister? There have been registered 4 cases of "questionanswer complexes" which have become headlines as a whole: So what made Teresa tick? Self-pity and lack of empathy; Out of her depth or an impossible job? She has still failed. Compound asyndetic headlines now are not used very often (4\%). As a rule they include a nominative component followed by its details or comments: The Times view on today's EU polls: Invisible Election; Speech unspun: what the PM really meant.

The most popular structure of modern headlines is a simple full sentence with a subject, a predicate and other sentence parts. Quite often these are expanded sentences full of various expressive means and stylistic devices: rhyme (Tussles in Brussels won respect for PM); alliteration (Bercow's bold agenda bender); slang words (Trump starts beef over missile tests before bonding over burgers); metaphors ("Russian" sting holds poison yet for Kurz; Predators flock to Snapchat, a "heaven" for child abuse); epithets (Lawyers play their part in flagging up dirty money; Next leader must be less wooden than the Maybot); irony (Impeachment could make Trump even more popular); similes (Purist Remainers are as bad as Brexiteers); break (And they are off ... with Johnson leading the field in race for №10); parenthesis (Harry (but not Meghan) will join president for lunch at the palace). The analysis has shown an extraordinary distribution of punctuation symbols which are aimed to draw attention to a particular part of the headline Suddenly, harshest critics full of praise for duty and dignity. 
Headlines-quotations are more frequent in the modern headlines than a century ago. A special attention should be paid to the character of these quotations. Usually they are bright and intriguing: Trump: I can't work with the Democrats plotting my downfall; Hospitals must close to save NHS, say doctors; EU putting lives at risk over Brexit, warns May.

Mononuclear nominative headlines are also not so frequent in today's newspapers as they used to be. However this type has become more extended and includes a whole range of stylistic devices: oxymorons (Warning from history to expect the unexpected); epithets (The meager legacy of a leader's short reign); rhyme (Miles of smiles); alliteration (From fashion to food).

Compound sentences with semantically coordinated or subordinate elements make successful, from my point of view, headlines as they usually contain a problem or interesting extra details about a burning issue which are able to involve the audience into reading the whole article. Compound headlines can substitute complex headlines with crossheadings in their informative function being more compact and making reading less time-consuming. For example: Walking holiday but premier on path to oblivion - a very emotional headline with a picture of Teresa May having a walk with her husband in a Scandinavian walking-style. However, through the use of a metaphor the journalist alludes to the fact that the Prime Minister will soon leave her office. One more headline of the same topic: Farewell to Downing Street after three years but she remains $P M$ for now. And an example of the same type with antithesis: Shed no tears for Teresa-she's not a victim of events but an abject failure. Some headlines of this type contain statements which are paradoxical and that is what stimulates the readers' interest: Fat people will have to diet if they want to see the doctor. For the sake of headline compression the journalists resort to apocope, apheresis and abbreviation: MMR jabs stockpiled as measles threat rises; May braced for historic defeat on Brexit D-Day; Don't refund all fraud victims, says top cop.

As the research has shown in the modern headlines there is a greater concentration of expressive means and stylistic devices - about $80 \%$ of headlines contain expressive means and stylistic devices of at least one language level (phonetic, morphological, lexical or syntactical).

\section{Conclusion}

In general, the newspaper headlines of both time periods are quite multifarious in their structural types and prevalence of stylistic means. It is demonstrative that the predominant structural types of the newspaper headlines are mononuclear nominative headlines, headlines-sentences which include both a subject and a predicate and complex headlines with crossheadings. These types are of an informative character and are aimed at statements of facts or giving details of 
the befallen events. Only $35 \%$ of all the excerpted items contain any stylistic devices as compared to the headlined from 2019 newspapers with a denser concentration of expressive means $-80 \%$. Moreover, the modern headlines are formed according to the structural pattern "simple headlines-sentences which include both a subject and a predicate" as number one in their frequency of use, followed by headlines-quotations, mononuclear nominative headlines and compound headlines with semantically coordinated or subordinate elements. From the perspective of the context together with structural types and frequency of the use of stylistic devices it is possible to make a conclusion about an increasing appealing role of modern headlines.

\section{Implications}

As it has been stated above, this paper is a part of a wider-in-scale research project. The implications for future research in this field can be to extend the analysis to a greater number of other languages including Belarusian, Russian and French. An interesting perspective for the complex research will be the revealing of common and specific tendencies in the evolution of newspaper headlines in different linguo-cultures. It will also make sense to extend the number of excerpted material for analysis. In this case the results would sound more convincing and significant.

\section{References:}

Develotte, C., \& Rechnieweski, E. (2001). Discourse analysis of newspaper headlines: a methodological framework for research into national representations. Retrieved from http://wjfms.ncl.ac.uk/titles.htm. [The Web Journal of French Media Studies 4/1]. Develotte, C., \& Rechnieweski, E. (2002). Expressions de l'identité nationale dans les titres de journaux : une étude comparative de journaux français et australiens pendant une période de crise. VIIe congrès international pour la recherche interculturelle. 92, 173-190.

Dor, D. (2003). On newspaper headlines as relevance optimizers. Journal of Pragmatics, 35, 695-721.

Gattani, A. (2007). Automated natural language headline generation using discriminative machine learning models. Retrieved from https://core.ac.uk/download/pdf/56366767. pdf.

Herman, E., \& Chomsky, N. (2002). Manufacturing consent: The political economy of the mass media. New York: Pantheon Books.

Iglikova, R. (2017). Headline patterns in viral web content - English-Bulgarian comparative case study. Crossing Borders and Bridging Gaps in English Language Teaching and Research. Series in Linguistics, Culture and FLT, 2, 71-84.

Iglikova, R. (2018). The evolution of the headline - from print to patterns and virality (an overview of research in English and Bulgarian). Studies in Linguistics, Culture and $E F L, 4,55-69$. 
Isani, S. (2011). Of headlines and headlinese: Towards distinctive linguistic and pragmatic genericity. ASp, la revue du GERAS, 60, 81-102

Kozhina, M. (2011). Stilistika sovremennoy russkoy rechi. Retrieved from https://media. ls.urfu.ru/561/1515/3522/4026.

Mardh, I. (1980). Headlinese: On the grammar of English front page headlines. Malmo: CWK Gleerup.

Marcoci, S. (2014). Some typical linguistic features of English newspaper headlines. Linguistic and philosophical investigations. Retrieved from https://www.questia.com/ library/journal/1P3-3332296621/some-typical-linguistic-features-of-english-newspaper. [ Electronic Academic Journal].

Reah, D. (2001). The language of newspapers. London; New-York: Routledge.

Van Dijk, T.A. (1985). Structure of news in the press. Discourse and communication: New approaches to the analysis of mass media discourse and communication. Berlin: Walter de Gruyter, 69-93.

Vorontsova, T. (2017). Novostnoy zagolovok kak reprezentant sobytiya. Politicheskaya Lingvistika, 6 (66), 21-25. 